\title{
Kappa-chain Gene Rearrangement in an Apparent T-lineage Lymphoma
}

\author{
Kyungsae Ha-Kawa, * Junichi Hara," Yumura Keiko,* Atsushi Muraguchi,‡ \\ Nobuaki Kawamura, $\ddagger$ Shigehiko Ishihara," Satoru Doi," and Hyakuji Yabuuchi* \\ *Department of Pediatrics, Osaka University Hospital; and ¥Institute for Molecular and Cellular Biology, \\ Osaka University, Osaka, Japan
}

\begin{abstract}
We describe a 10-yr-old boy with T-lineage non-Hodgkin's lymphoma. He had a mediastinal mass, swollen supraclavicular lymph nodes, and pleural effusion. A supraclavicular lymph node biopsy under light microscopy showed a malignant lymphoma of diffuse lymphoblastic type. Most of the cells taken from the malignant pleural effusion expressed $T$ cell-associated antigens such as Leu-1 and OKT 8. To confirm these antigens as T-lineage lymphoma, we examined genomic DNA from malignant cells obtained from the pleural effusion. As was expected, $T$ cell receptor $\beta$-chain gene rearrangements were demonstrated. However, when the immunoglobulin gene organization was analyzed, we detected rearrangements in both the heavy- and kappa-chain genes. To our knowledge, this is the first case in which kappachain gene rearrangement was detected in apparent $T$-lineage cells. These findings provide important information relating to determination of the cellular lineage of lymphoid malignancy.
\end{abstract}

\section{Introduction}

Histologic and immunological evaluation of tissue biopsies and/ or cell suspension have proven valuable in the diagnosis and classification of lymphoid neoplasms. More recently, detection of $\mathrm{Ig}$ and $\mathrm{T}$ cell receptor $\beta$-chain $\left(\mathrm{T}_{\beta}\right)^{1}$ gene rearrangements has been shown to be an effective procedure for identifying monoclonality and the cellular lineage of lymphoid cells even when conventional studies give an ambiguous diagnosis (1-7).

After we reported the first case of $T$ cell acute lymphoblastic leukemia (ALL) with $\mathrm{C}_{\mu}$ gene rearrangement in newly diagnosed patients (8), analogous cases were reported. The incidence of this event among $\mathrm{T}$-lineage leukemias can be estimated at $\sim 20 \%$ $(2,9)$. Similarly, $\mathrm{C} \mu$ gene rearrangement was also observed in acute nonlymphocytic leukemia $(10,11)$. However, such Ig gene rearrangements in non-B-lineage cells reported so far are restricted to heavy-chain genes. For the most part, a unique pattern

Address correspondence to Kyungsae Ha-Kawa, Department of Pediatrics, Osaka University Hospital, 1-1-50, Fukushimaku, Osaka, Japan 553.

Received for publication 31 December 1985 and in revised form 6 August 1986.

1. Abbreviations used in this paper: $\mathrm{ALL}$, acute lymphoblastic leukemia; CALLA, common acute lymphoblastic leukemia antigen; $C_{K}$, kappachain gene; Ia, I-region-associated antigen; $\mathrm{J}_{\mathrm{H}}$, heavy-chain-joining gene; $\mathrm{T}_{\beta}$, T cell-receptor $\beta$-chain; $\mathrm{T}_{\beta} \mathrm{mRNA}$, T cell-receptor $\beta$-chain gene mRNA.

J. Clin. Invest.

(c) The American Society for Clinical Investigation, Inc. $0021-9738 / 86 / 12 / 1439 / 04 \$ 1.00$

Volume 78, December 1986, 1439-1442 of single allelic rearrangement has been observed (12). Based on these findings, it is clear that the mere demonstration of rearranged heavy-chain genes is not sufficient to establish a B-cell lineage.

In contrast, light-chain gene rearrangements have been thought to represent a more definitive assessment of B-lineage commitment because of the developmental hierarchy of Ig genes (13). Here, we present the first case of apparent T-lineage lymphoma, whose malignant cells showed heavy- and light-chain gene rearrangements in addition to $\mathrm{T}$ cell receptor $\beta$-chain gene rearrangements.

\section{Methods}

A 10-yr-old boy was presented with a large mediastinal mass, swollen supraclavicular lymph nodes, and pleural effusion. Biopsy specimens of a supraclavicular lymph node revealed non-Hodgkin's lymphoma of diffuse lymphoblastic type. Cells obtained through thoracocentesis were also positive for the Papanicolaou's staining. No malignant cells were detected in the peripheral blood or bone marrow.

Immunologic phenotype. Immunologic studies were performed on the cells obtained from the pleural effusion. Mononuclear cells were prepared after Ficoll-Hypaque gradient centrifugation, and reactivity with a panel of monoclonal antibodies was carried out as previously described (8).

DNA analysis. Genomic DNA was extracted from the mononuclear cells and was digested with Eco RI or Bam $\mathrm{HI}$ restriction endonuclease, which are known to permit demonstration of both rearranged and germline configuration of $I g$ and $T_{\beta}$ genes $(1,2,5,7)$. Digested DNA was sizefractionated by agarose gel electrophoresis and transferred to nitrocellulose filter (14). Such filter-bound DNA fragments were then hybridized to nick-translated ${ }^{32} \mathrm{P}$-DNA probes of Ig genes and $\mathrm{T}_{\beta}$ genes (15). The human Ig gene probes used are the heavy-chain-joining gene $\left(J_{H}\right)$ probe $(3-k b$ embryonic Eco RI-Hind III $\mathrm{J}_{\mathbf{H}}$-containing fragment) and the $\mathrm{k}$ probe (2.5-kb embryonic Eco RI kappa-chain gene $\left(\mathrm{C}_{\mathrm{K}}\right)$-containing fragment). The human $\mathrm{T}_{\beta}$ gene probe was the Bgl II-Eco RV fragment of the CDNA clone YT-35 that contained the constant region of the $T$ cell receptor gene (0.8-kb Bgl II-Eco RV fragment). $J_{H}$ and $C_{K}$ germ-line clones were kindly provided by Dr. P. Leder $(16,17)$ (Department of Genetics, Harvard Medical School, Boston, MA). The cDNA clone YT-35 was kindly provided by Dr. T. Mak (18) (Department of Medical Biophysics, Ontario Cancer Institute, Toronto, Canada).

$R N A$ analysis. Total cellular RNA was extracted from cells in the presence of guanidine thiocyanate (19). $10 \mu \mathrm{g}$ of each RNA sample was separated to size by electrophoresis in 1\% agarose gel. The size-separated fragments were transferred to nitrocellulose filter by Northern techniques and hybridized to radiolabeled ${ }^{32}$ P-DNA probes of the $T_{\beta}$ and the $C_{K}$ described above.

\section{Results}

As shown in Table I, most of the patient's lymphoma cells expressed Leu-1 (64.8\%) and OKT 8 (70.3\%). A small fraction of 
Table I. Results of Immunologic Studies

\begin{tabular}{llr}
\hline & Surface marker & \% Fluorescent cells \\
\hline T-lineage & OKT 3 & 6.0 \\
& 4 & 33.6 \\
& 8 & 70.3 \\
& 11 & 35.6 \\
B-lineage & Leu-1 & 64.8 \\
& B 1 & 9.6 \\
& B 4 & 15.7 \\
Myeloid & SIg & 7.7 \\
& My 7 & 6.5 \\
Others & Mo 2 & 12.3 \\
& Ia & 6.5 \\
& CALLA & 5.0 \\
\hline
\end{tabular}

sIg, surface immunoglobulin; CALLA, common acute lymphoblastic leukemia antigen.

the cells reacted with OKT 4 and OKT 11 . No other antigens, such as B-lineage and myeloid-lineage, were detected in most of the patient's cells.

The $J_{H}$ probe recognized a rearrangement band with a faint band that corresponds to the germ-line configuration when genomic DNA was digested with Eco RI (Fig. 1). The $\mathrm{C}_{\mu}$ probe (8) also detected two rearranged bands (data not shown). This $\mathrm{J}_{\mathrm{H}}$ probe identified an 18-kb Eco RI fragment in the germ-line DNA. In parallel studies, seven cases of T-lineage leukemia showed the germ-line configuration of Ig genes, and 19 of 20 cases with common ALL (I-region-associated antigen [ $\left.\mathrm{Ia}^{+}\right]$, common acute lymphoblastic leukemia [CALLA $\left.{ }^{+}\right]$) demonstrated Ig gene rearrangements (20). When the $C_{\mu}$ probe was used after digestion with Bam $\mathrm{HI}$, a single rearranged band was also found with deletion of the other allele (Fig. 1). This $\mathrm{C}_{\mu}$ probe consistently detected a $12.5-\mathrm{kb}$ Bam HI fragment for the germ-line $k$ genes (2).
In the human germ-line $T$ cell-receptor $\beta$-chain genome, there are two constant-region genes $\left(\mathrm{C}_{\beta} 1\right.$ and $\left.\mathrm{C}_{\beta} 2\right)(18)$. The $\mathrm{Bgl}$ II-Eco RV fragment of the cDNA clone YT-35 ( $\mathrm{T}_{\beta}$ probe) detected 11-kb $\left(C_{\beta} 1\right)$ and 4-kb $\left(C_{\beta} 2\right)$ Eco RI germ-line fragments, and one 24-kb Bam HI germ-line fragment containing both $\mathrm{C}_{\beta} 1$ and $\mathrm{C}_{\beta} 2(5,21)$. After Eco RI digestion and hybridization with the $T_{\beta}$ probe, the patient's DNA showed one rearrangement band with a germ-line configuration of the 4-kb fragment. This indicates rearrangement of one allele and deletion of the other $\mathrm{C}_{\beta} 1$ allele, because there is an Eco RI restriction site just before $\mathrm{C}_{\beta} 2$. The 4-kb band does not move, even in $\mathrm{C}_{\beta} 2$ rearrangement (Fig. 1) (21). In addition, we detected two rearranged bands in the experiment using Bam $\mathrm{HI}$ digestion (Fig. 1). These findings indicate that both alleles of the $T_{\beta}$ gene were used in the present case.

Fig. 2 shows the results of Northern blot analysis. Similar to RNA from a $\mathrm{T}$ cell line (Fig. 2, lane $H S B$ ), the RNA sample from the present case (lane $P$ ) contained a $1.3-\mathrm{kb}$ T cell-receptor $\beta$-chain gene mRNA ( $\mathrm{T}_{\beta} \mathrm{mRNA}$ ), which has been shown to be a functional mRNA transcript $(22,23)$. However, unlike $T_{\beta}$ mRNA, no $C_{\mu}$ mRNA could be detected in this particular case. RNA from a B-cell line (lane Jijoye; $\mathbf{s I g} \mu^{+}, \mathbf{k}^{+}$) demonstrated 1.0-kb $C_{\mathrm{K}} \mathrm{mRNA}$. RNA from a non-T-lineage cell line (lane $U$ 937) and a newly diagnosed common ALL case (lane $A L L$ ) were also examined as controls. This common ALL had rearrangements of the Ig heavy-chain and $\mathrm{T}_{\beta}$ genes, and the germline configuration of the Ig light-chain gene. As shown in Fig. 2 , no transcripts of the $T_{\beta}$ and $C_{\mu}$ genes were observed in either instance.

\section{Discussion}

Our finding of kappa gene rearrangement in an apparent Tlineage lymphoma provides new information relating to determination of the cellular lineage of lymphoid malignancies. Ig gene rearrangement is an essential property of cells of B-lineage, and detection of Ig gene rearrangements has been used to define the origin of immature cells and find monoclonality in mixed populations (1-4). Ig gene rearrangement is also observed in
Ig Gene

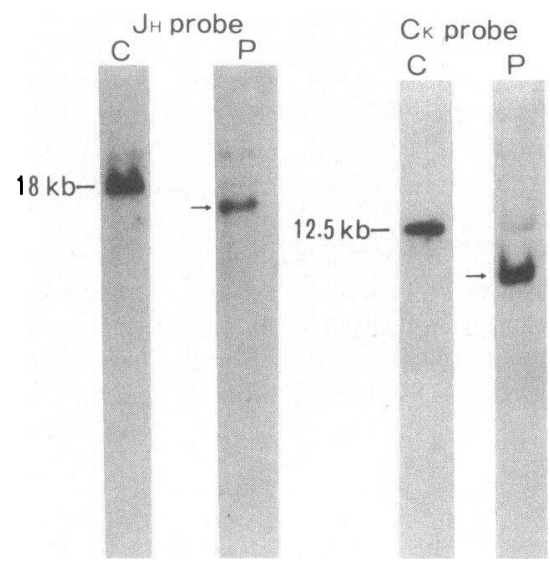

Eco RI
Bam HI

\section{$\mathrm{T}_{\beta}$-Chain Gene}

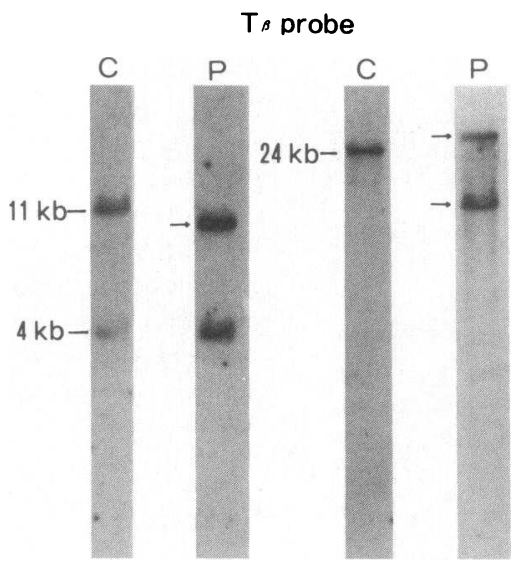

Eco RI
Figure 1. Southern blot analysis to detect germline and rearranged Ig genes and $T_{\beta}$-chain genes in control $(C)$ and lymphoma cell DNA $(P)$. The $\mathrm{J}_{\mathbf{H}}$ probe, containing a 3-kb germ-line Eco RI-Hind III fragment, detected an 18-kb Eco RI fragment as germ-line (solid line) and rearranged allele (arrow). The $C_{K}$ probe, containing a $2.5-\mathrm{kb}$ embryonic Eco $\mathrm{RI} \mathrm{C}_{\mathrm{K}}$-containing fragment, recognized a $12.5-\mathrm{kb}$ Bam HI fragment for the germ-line genes (control, $C$, solid line). An arrow indicates rearranged allele. Similarly, the $\mathrm{T}_{\beta}$ probe, containing a $0.8-\mathrm{kb} \mathrm{Bgl} \mathrm{II-}$ Eco RV fragment of the DNA clone YT-35, detected 11-kb and 4-kb Eco RI germ-line fragments and one 24-kb Bam HI germ-line fragment (solid) and rearranged alleles (arrow). 


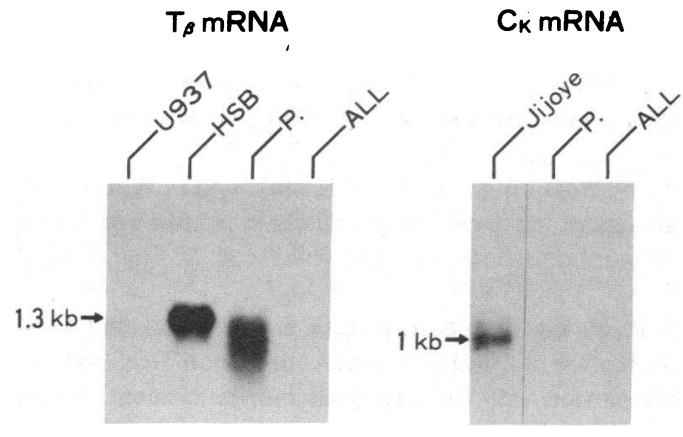

Figure 2. Northern blot analysis to detect transcript of $T$ cell receptor $\beta$-chain genes and kappa-chain genes. RNA from a $T$ cell line (lane $H S B$ ) and the present case (lane $P$ ) expressed a functional 1.3-kb $\mathrm{T}_{\beta}$ gene transcript. No $T_{\beta}$ mRNA was detected in a non-T-lineage cell line (lane U937) and a common ALL case in which IgH and $\mathrm{T}_{\beta}$ genes were rearranged (lane $A L L$ ). Jijoye (B cell line, $\operatorname{sIg} \mu^{+}, \mathrm{k}^{+}$) expressed a 1-kb mRNA of IgK genes, while no transcript was detected in lane $P$ and lane $A L L$.

non-B-lineage cells, although such rearrangement is fairly restricted to the heavy-chain gene (12). Therefore, Ig gene rearrangement alone is not sufficient to establish B cell lineage. For assignment of a B-lineage commitment, the light-chain gene must undergo rearrangements on the basis of the developmental hierarchy of Ig genes $(1,13)$.

The $\beta$-chain of the $\mathrm{T}$ cell-receptor gene shares certain homologies with Ig genes, including rearrangement during $\mathrm{T}$ cell development $(5-7,18,21)$. With the cloning of $T_{\beta}$ genes, it has become possible to study the organization of $\mathrm{T}_{\beta}$ genes in individual cells and determine the cellular lineage of given cells. Rearrangements of $T_{\beta}$ genes are consistently observed in T-lineage leukemia and lymphoma $(5,7,21)$.

Tawa et al. reported that $T_{\beta}$ gene rearrangements were also detected in 10 of 39 patients with common ALL $\left(\mathrm{Ia}^{+}, \mathrm{CALLA}{ }^{+}\right)$. The patterns of rearrangement, however, were somewhat unique compared with those of T-lineage leukemia. None of the 10 cases had rearranged bands of $C_{\beta} 1$ genes, which seems to be more characteristic of $\mathrm{T}$-lineage leukemia (21).

Using morphological and immunological studies, we diagnosed the present case as having T-lineage non-Hodgkin's lymphoma. Phenotypically, only T-lineage-associated markers such as Leu-1 and OKT 8 were detected on the cell surface. In addition, we found a characteristic rearrangement pattern of $T_{\beta}$ genes in the Eco RI experiment. More definitively, we were able to show a functional 1.3-kb $\mathrm{T}_{\beta}$ gene mRNA in Northern blot analysis (Fig. 2).

Contrary to these findings, when the patient's DNA was further analyzed using the $J_{H}$ and $C_{\mu}$ probes, both the heavy- and light-chain genes were found to be rearranged. The retention of a faint germ-line band in each experiment (Fig. 1) could have been due to contamination by normal cells.

To our knowledge, this represents the first example of detection of k-gene rearrangement in cells of apparent $\mathrm{T}$-lineage. This finding is indeed different from the previous studies in nonB-lineage cells, where the rearrangement of Ig genes was restricted to the heavy-chain gene (8-12). In this particular case, we could not detect a real message of the rearranged k-genes.

The results presented here suggest that one should always exercise caution when the cellular lineage is determined at the DNA level and is used to predict the prognosis and determine the therapy.

\section{Acknowledgments}

We are indebted to Dr. T. Kishimoto and Mr. N. Tsunekawa of the Institute of Molecular and Cellular Biology, Osaka University, for their invaluable help.

This work was supported in part by a Grant-in-Aid for Cancer Research from the Ministry of Education, Science and Culture, and the Ministry of Health and Welfare of Japan.

\section{References}

1. Korsmeyer, S. J., A. Arnold, A. Bakhshi, J. V. Ravetch, U. Siebenlist, P. A. Hieter, S. O. Sharrow, T. W. LeBien, J. H. Kersey, D. G. Poplack, P. Leder, and T. A. Waldmann. 1983. Immunoglobulin gene rearrangement and cell surface antigen expression in acute lymphocytic leukemias of T cell and B cell precursor origins. J. Clin. Invest. 71:301313.

2. Ha, K., N. Hozumi, A. Hrincu, and E. W. Gelfand. 1985. Lineage specific classification of leukemia: results of the analysis of sixty cases of childhood leukemia. Br. J. Haematol. 61:237-249.

3. Arnold, A., J. Cossman, A. Bakhshi, E. S. Jaffe, T. A. Waldmann, and S. J. Korsmeyer. 1983. Immunoglobulin-gene rearrangements as unique clonal markers in human lymphoid neoplasms. N. Engl. J. Med. 309:1593-1599.

4. Cleary, M. L., J. Chao, R. Warnke, and J. Sklar. 1984. Immunoglobulin gene rearrangement as a diagnostic criterion of B-cell lymphoma. Proc. Natl. Acad. Sci. USA. 81:593-597.

5. Minden, M., B. Toyonaga, K. Ha, Y. Yanagi, E. W. Gelfand, and T. Mak. 1985. Somatic rearrangement of the T-cell antigen receptor gene in human T-cell malignancies. Proc. Natl. Acad. Sci. USA. 82: $1224-1227$.

6. Bertness, V., I. Kirsch, G. Hollis, B. Johnson, and P. A. Bunn. 1985. T-cell receptor gene rearrangements as clinical markers of human T-cell lymphomas. N. Engl. J. Med. 313:534-538.

7. Waldmann, T. A., M. M. Davis, K. F. Bongiovanni, and S. J. Korsmeyer. 1985. Rearrangements of genes for the antigen receptor on T-cells as markers of lineage and clonality in human lymphoid neoplasms. N. Engl. J. Med. 313:776-783.

8. Ha, K., M. Minden, N. Hozumi, and E. W. Gelfand. 1984. Immunoglobulin $\mu$-chain gene rearrangement in a patient with $T$-cell acute lymphoblastic leukemia. J. Clin. Invest. 73:1232-1236.

9. Kitchingman, G. R., U. Rovigatti, A. M. Mauer, S. Melvin, S. B. Murphy, and S. Stass. 1985. Rearrangement of immunoglobulin heavy chain genes in T cell acute lymphoblastic leukemia. Blood. 65:725-729.

10. Ha, K., M. Minden, N. Hozumi, and E. W. Gelfand. 1984: Immunoglobulin gene rearrangement in acute myelogenous leukemia. Cancer Res. 44:4658-4660.

11. Rovigatti, U., J. Mirro, G. Kitchingman, G. Dahl, J. Ochs, S. Murphy, and S. Stass. 1984. Heavy-chain immunoglobulin gene rearrangement in acute nonlymphocytic leukemia. Blood. 63:1023-1027.

12. Ha, K., M. Minden, N. Hozumi, and E. W. Gelfand. 1986. Single allelic $\mathrm{C} \mu$ gene rearrangements in patients with $\mathrm{T}$ cell and undifferentiated leukemia. Leuk. Res. 10:1-8.

13. Korsmeyer, S. J., P. A. Hieter, J. V. Ravetch, D. G. Poplack, T. A. Waldmann, and P. Leder. 1981. Developmental hierarchy of immunoglobulin gene rearrangements in human leukemic pre-B-cells. Proc. Natl. Acad. Sci. USA. 78:7096-7100.

14. Southern, E. M. 1975. Detection of specific sequences among DNA fragments separated by gel electrophoresis. J. Mol. Biol. 98:503517.

15. Rigby, P. W. J., M. Dieckmann, C. Rhodes, and P. Berg. 1977. 
Labeling deoxyribonucleic acid to high specific activity in vitro by nick translation with DNA polymerase I. J. Mol. Biol. 113:237-251.

16. Ravetch, J. V., U. Siebenlish, S. J. Korsmeyer, T. A. Waldmann, and P. Leder. 1981. The structure of the human immunoglobulin mu locus: characterization of embryonic and rearranged $\mathrm{J}$ and $\mathrm{D}$ genes. Cell. 27:583-591.

17. Hieter, P. A., E. E. Max, J. G. Seidman, J. F. Maizel, and P. Leder. 1980. Cloned human and mouse kappa immunoglobulin constant and $\mathrm{J}$ region genes conserve homology in functional segments. Cell. 22: 197-207.

18. Yanagi, Y., Y. Yoshikai, K. Leggett, S. P. Clark, I. Aleksander, and T. Mak. 1984. A human T cell-specific cDNA clone encodes a protein having extensive homology to immunoglobulin chains. Nature (Lond.). 308:145-149.

19. Chirgwin, J. M., A. E. Przbyla, R. J. MacDonald, and W. J.
Rutter. 1979. Isolation of biologically active ribonucleic acid from sources enriched in ribonuclease. Biochemistry. 18:5294-5299.

20. Hara, J., K. Ha-Kawa, K. Yumura, S. Ishihara, S. Doi, and H. Yabuuchi. 1986. Further heterogeneity of childhood common acute lymphoblastic leukemia. Jpn. J. Cancer Res. 77:28-31.

21. Tawa, A., N. Hozumi, M. Minden, T. Mak, and E. W. Gelfand. 1985. Rearrangement of the T-cell receptor $\beta$-chain gene in non-T-cell, non-B-cell acute lymphoblastic leukemia of childhood. N. Engl. J. Med. 313:1033-1037.

22. Clark, S. P., Y. Yoshikai, S. Taylor, G. Siu, L. Hood, and T. W. Mak. 1984. Identification of a diversity segment of human T-cell receptor $\beta$-chain, and comparison with the analogous murine element. Nature (Lond.). 311:387-389.

23. Yoshikai, Y., D. Analoniou, S. P. Clark, Y. Yanagi, R. Sangster, P. Van den Elsen, C. Terhorst, and T. W. Mak. 1984. Sequence and expression of transcripts of the human T-cell receptor $\beta$-chain genes. Nature (Lond.). 312:521-524. 